\title{
ÁCIDOS ORGÂNICOS DE BAIXA MASSA MOLAR EM SOLOS E MATERIAIS ORGÂNICOS
}

\author{
Gabriela Lúcia Pinheiro*, Carlos Alberto Silva, José Maria de Lima e Alisson Lucrécio da Costa \\ Departamento de Ciência do Solo, Universidade Federal de Lavras, 37200-000 Lavras - MG, Brasil \\ Adelir Aparecida Saczk \\ Departamento de Química, Universidade Federal de Lavras, 37200-000 Lavras - MG, Brasil
}

Recebido em 21/5/12; aceito em 5/10/12; publicado na web em 6/2/13

\begin{abstract}
LOW MOLECULAR WEIGHT ORGANIC ACIDS IN SOILS AND ORGANIC MATERIALS. Determination of organic acids in soils and organic materials is important due to the important role they play in improving the soil's physical, chemical and microbiological conditions. This study identified and quantified low molecular weight organic acids (LMWOA) in soils (dystroferric Red Latosol, dystrophic Red-Yellow Latosol and Quartzarenic Neosol) and organic materials (cow, pig, chicken, quail and horse manures, sawdust, coconut fiber, pine bark, coffee husks, biochar, organic substrate, sewage sludges 1 and 2, garbage compost, pig slurry compost). The following acids were identified: acetic, citric, D-malic, formic, fumaric, maleic, malonic, oxalic, quinic, shikimic, succinic and tartaric.
\end{abstract}

Keywords: manures; plant residues; liquid chromatography.

\section{INTRODUÇÃO}

Em lavouras, agroindústrias e em plantas municipais de tratamento de lixo e de esgoto são produzidos resíduos de diferentes composições químicas e graus de humificação. Em solos, os resíduos orgânicos liberam quantidades variáveis de carbono solúvel em água e parte desse carbono é constituída de AOBMM, que são produzidos durante a decomposição dos resíduos de plantas e animais, em função do ataque microbiano a esses compartimentos de carbono. Em solos mais férteis e com $\mathrm{pH}$ próximo da neutralidade, a decomposição da maioria dos resíduos orgânicos é aumentada; esses fatores exercem influência também sobre a atividade microbiana, alterando a produção de AOBMM. ${ }^{1-3}$

No solo, são encontrados os ácidos oxálico, cítrico, fórmico, acético, málico, succínico, maleico, acotínico, fumárico, gálico, vanílico, benzoico, fumárico e chiquímico $, 4,5$ em concentrações variáveis, que representam menos de $3 \%$ do carbono orgânico dissolvido (COD) na solução do solo, ${ }^{6}$ muito embora possam contribuir com até $5 \%$ do COD em espodossolos, ${ }^{1,5}$ que são solos que se caracterizam pela migração de alumínio e/ou ferro, em presença de matéria orgânica, para o horizonte subsuperficial. ${ }^{7}$ Em resíduos, as proporções e tipos de AOBMM variam de um material para outro, sendo comum em resíduos vegetais a presença dos ácidos oxálico, tartárico, acotínico, málico, cítrico, acético, lático, ascórbico e fórmico, havendo predominância, de acordo com o resíduo analisado, dos ácidos acotínico, cítrico e málico. ${ }^{8,9}$

Os ácidos orgânicos provenientes de plantas têm sido o foco de muitas pesquisas. ${ }^{10}$ Entretanto, informações sobre a concentração e o tipo de ácidos orgânicos em solos tropicais, principalmente em condições aeróbias e em resíduos, ainda são incipientes. A existência dos AOBMM em solos aeróbios é transitória ${ }^{11} \mathrm{e}$, possivelmente, essa seja a principal causa de carência de estudos envolvendo AOBMM em solos do Brasil, além do fato de os AOBMM se apresentarem em baixas concentrações nos solos,,$^{12}$ o que pode dificultar a sua determinação. Os ácidos orgânicos alifáticos de cadeia curta, por exemplo, são voláteis e possuem meia-vida em solo que varia de 1 a 12 h; esses compostos são rapidamente mineralizados pela comunidade microbiana do solo. ${ }^{13-16}$

*e-mail: gabiquimica8@yahoo.com.br
Os AOBMM são moléculas reativas que desempenham inúmeras funções no solo. A maioria das funções está associada aos ácidos di e tricarboxílicos, como málico, oxálico e cítrico, ${ }^{17}$ embora os ácidos monocarboxílicos (fórmico, acético, propiônico, lático e butírico) sejam frequentemente encontrados em concentrações mais elevadas (até $1000 \mu \mathrm{mol} \mathrm{L}{ }^{-1}$ ) na solução do solo. ${ }^{6}$ Devido à carga negativa associada aos grupos carboxílicos, os AOBMM podem ser sorvidos na fase sólida do solo. ${ }^{18}$ Além da adsorção, os AOBMM também podem ser ligar às superfíicies de minerais de um modo quase irreversível (fixação), o que implica, em curto prazo, numa baixa biodegradação desses ácidos. ${ }^{19,20}$ Em contraste, os ácidos orgânicos livres ou trocáveis no solo podem ser rapidamente mineralizados, ${ }^{20}$ de modo que há remoção contínua de ácidos orgânicos da solução, o que implica em nova liberação de ácidos da fase sólida para a líquida, para recompor as concentrações originais de ácidos orgânicos na solução. ${ }^{18}$

Em solo, os ácidos orgânicos associados às argilas, em ligações de alta e baixa energia, à matéria orgânica, em complexos argila-húmus, aos precipitados e os associados à biomassa microbiana constituem o fator quantidade $(\mathrm{Q})$. O fator intensidade (I), que representa as concentrações de AOBMM na solução do solo, refere-se aos compartimentos de AOBMM ligados a complexos solúveis organo-metálicos, complexos organo-orgânicos solúveis e os ácidos livres na solução do solo. A relação entre os fatores Q e I determina, para efeito de caracterização, as quantidades de AOBMM extraídas dos solos. Desse modo, é esperado maior teor de ácidos no solo com maior teor de matéria orgânica, que atua como substrato para os microrganismos produzirem os AOBMM, e nos materiais orgânicos mais ricos em nutrientes e em compostos lábeis, já que a atividade microbiana é influenciada pela composição química do material orgânico. ${ }^{2}$

Este estudo teve como objetivo identificar e quantificar AOBMM em amostras de solos, estercos, resíduos vegetais, lodo de esgoto, turfa, carvão, substrato, compostos de dejeto e de lixo.

\section{PARTE EXPERIMENTAL}

\section{Materiais utilizados no estudo}

Os solos utilizados no estudo foram o Latossolo Vermelho distroférrico (LVdf, textura argilosa; 66\% de argila), o Latossolo VermelhoAmarelo distrófico (LVAd, textura média, 18\% de argila) e o Neossolo 
Quartzarênico (NQ, textura arenosa, 8\% de argila) cujas amostras foram coletadas na camada de $0-20 \mathrm{~cm}$. O LVdf encontra-se sob cobertura vegetal de floresta tropical subperenefólia; o LVAd também se encontra sob vegetação natural e o NQ encontra-se sob vegetação de cerrado stricto sensu. Os solos distinguem-se uns dos outros principalmente em relação à textura e ao teor de carbono (Tabela 1). Além dos solos, foram utilizadas as seguintes amostras de materiais orgânicos: estercos de bovino, suíno, galinha, codorna e cavalo, serragem, casca de pinus, fibra de coco, casca de café, turfa, carvão, substrato, lodo de esgoto 1, lodo de esgoto 2, composto de lixo e composto de dejetos de suínos. Após a coleta dos solos e dos resíduos orgânicos, as amostras foram secas em estufa a $70^{\circ} \mathrm{C}$, moídas em moinho tipo Wiley, peneiradas (abertura de malha de $2 \mathrm{~mm}$ ) e armazenadas em dessecador.

$\mathrm{Na}$ fase de caracterização desses materiais, foram utilizadas as marchas analíticas descritas em Higashikawa et al. ${ }^{21} \mathrm{e}$ em Tedesco et al., ${ }^{22} \mathrm{com}$ as seguintes modificações: o $\mathrm{pH}$ e a condutividade eletrolítica foram determinados utilizando-se a relação resíduo:água de 1:5 (m/v). Para a extração dos teores de carbono orgânico extraível com água (COEA), foi utilizada a marcha analítica proposta por Scaglia e Adani, ${ }^{23}$ com as seguintes modificações: na fase de extração, foram utilizadas $10 \mathrm{~g}$ de material, que foram misturadas a $100 \mathrm{~mL}$ de água ultrapura (purificada em sistema Milli Q) e agitadas a 125 rpm por $2 \mathrm{~h}$; em sequência, as amostras foram centrifugadas a 9000 rpm, durante 30 min e filtradas em membrana com diâmetro de poro de $0,45 \mu \mathrm{m}$. Os teores de COEA e de carbono total nos materiais foram determinados no analisador elementar modelo Vario TOC
Cube, utilizando-se, no caso dos resíduos, 3 a $5 \mathrm{mg}$ de amostra. As marchas analíticas utilizadas para caracterizar o grau de fertilidade das amostras de solo $(0-20 \mathrm{~cm})$ foram as descritas em Silva et al. ${ }^{24}$ à exceção do teor de carbono, que também foi determinado em analisador elementar modelo Vario TOC Cube, com utilização de cerca de $20 \mathrm{mg}$ de amostra.

Os principais atributos químicos e físico-químicos dos solos são apresentados na Tabela 1 e dos materiais orgânicos, na Tabela 2.

\section{Extração de ácidos orgânicos}

O protocolo analítico utilizado na extração de AOBMM dos solos e dos resíduos foi adaptado de van Hees et al. ${ }^{16}$ No processo de extração de ácidos orgânicos, realizado em triplicata, foi utilizada $1,0 \mathrm{~g}$ de solo, que foi misturada a $5 \mathrm{~mL}$ de solução $\mathrm{KH}_{2} \mathrm{PO}_{4} 100 \mathrm{mmol}$ $\mathrm{L}^{-1}(\mathrm{pH}=4,2)$; no caso dos resíduos orgânicos, foram pesadas $2,5 \mathrm{~g}$, que foram misturadas a $12,5 \mathrm{~mL}$ de solução de $\mathrm{KH}_{2} \mathrm{PO}_{4} 100 \mathrm{mmol} \mathrm{L}^{-1}$ $(\mathrm{pH}=4,2)$; as amostras foram acondicionadas em tubos de centrífuga de $35 \mathrm{~mL}$, agitadas a $150 \mathrm{rpm}$ por $30 \mathrm{~min}$ e centrifugadas em 9000 rpm, durante 15 min. Após essa etapa, os extratos foram filtrados em membrana com diâmetro de poro de $0,45 \mu \mathrm{m}$ e armazenadas para análise cromatográfica.

\section{Análise cromatográfica}

A separação cromatográfica foi realizada pela técnica HPLC, em

Tabela 1. Principais atributos químicos e físico-químicos das amostras de solo

\begin{tabular}{|c|c|c|c|c|c|c|c|c|c|c|c|}
\hline \multirow{2}{*}{ Solo } & \multirow{2}{*}{$\mathrm{pH}$} & $\mathrm{CE}$ & $\mathrm{C}$ & $\mathrm{N}$ & $\mathrm{V}$ & COEA & $\mathrm{P}\left(\mathrm{Mehlich}^{-1}\right)$ & $\mathrm{K}$ & CTC & $\mathrm{Ca}^{2+}$ & $\mathrm{Mg}^{2}$ \\
\hline & & $\mathrm{dS} \mathrm{m}^{-1}$ & \multicolumn{3}{|c|}{ 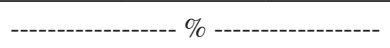 } & --------- & $\mathrm{mg} \mathrm{kg}^{-1}$ & ------ & \multicolumn{3}{|c|}{ - } \\
\hline $\operatorname{LVdf}^{(1)}$ & 4,2 & 0,12 & 4,4 & 0,4 & 3 & 1978 & 2 & 59 & 158 & 2 & 2 \\
\hline $\operatorname{LVAd}^{(2)}$ & 5,3 & 0,03 & 0,9 & 0,3 & 8 & 715 & 1 & 11 & 28 & 1 & 1 \\
\hline $\mathrm{NQ}^{(3)}$ & 5,4 & 0,04 & 1,2 & 0,2 & 16 & 544 & 9 & 22 & 54 & 7 & 1 \\
\hline
\end{tabular}

CE, condutividade eletrolítica; $\mathrm{V}$, saturação por bases; COEA, carbono orgânico extraível com água; CTC, capacidade de troca de cátions; ${ }^{(1)}$ Latossolo Vermelho distroférrico; ${ }^{(2)}$ Latossolo Vermelho-Amarelo distrófico; ${ }^{(3)}$ Neossolo Quartzarênico.

Tabela 2. Principais atributos químicos e físico-químicos dos materiais orgânicos utilizados no estudo

\begin{tabular}{|c|c|c|c|c|c|c|c|}
\hline Amostra & $\mathrm{C}(\%)$ & COEA $\left(\mathrm{mg} \mathrm{kg}^{-1}\right)$ & $\mathrm{CTC}\left(\mathrm{mmol}_{\mathrm{c}} \mathrm{dm}^{-3}\right)$ & $\mathrm{N}(\%)$ & $\mathrm{C} / \mathrm{N}$ & pH em água & $\left.\mathrm{CE}(\mathrm{dS} \mathrm{m})^{-1}\right)$ \\
\hline Esterco de galinha & 22,7 & 31810 & 568 & 4,8 & 4,7 & 7,1 & 6,6 \\
\hline Esterco de suíno & 26,3 & 13050 & 731 & 2,0 & 13,1 & 7,7 & 2,8 \\
\hline Esterco de cavalo & 39,4 & 18370 & 532 & 0,6 & 65,6 & 7,9 & 1,8 \\
\hline Esterco de bovino & 23,9 & 15910 & 889 & 1,8 & 13,2 & 8,9 & 6,0 \\
\hline Esterco de codorna & 25,5 & 32110 & 487 & 2,4 & 10,6 & 7,1 & 7,4 \\
\hline Serragem & 44,6 & 3580 & 627 & 0,3 & 131 & 4,4 & 1,5 \\
\hline Fibra de coco & 45,4 & 9320 & 497 & 0,4 & 113 & 5,0 & 1,3 \\
\hline Casca de pinus & 45,8 & 5902 & 495 & 0,4 & 101 & 4,2 & 0,2 \\
\hline Casca de café & 42,0 & NI & 602 & 3,0 & 14,0 & 4,7 & 6,3 \\
\hline Carvão & 80,7 & 736 & 702 & 0,7 & 115 & 8,0 & 0,2 \\
\hline Lodo 1 & 19,8 & 3228 & 432 & 2,2 & 9,0 & 3,4 & 3,3 \\
\hline Lodo 2 & 21,4 & NI & 164 & 2,1 & 10,3 & 5,4 & NI \\
\hline Substrato & 38,0 & 292 & 614 & 0,2 & 180 & 4,7 & 3,7 \\
\hline Turfa & 7,8 & 1356 & 254 & 1,2 & 6,5 & 5,1 & 0,1 \\
\hline Composto de lixo & 18,4 & NI & 651 & 2,4 & 7,7 & NI & NI \\
\hline Composto de dejetos de suínos & 29,8 & 4700 & 542 & 1,6 & 19,2 & 6,2 & 1,0 \\
\hline
\end{tabular}

COEA, carbono orgânico extraível com água; CTC, capacidade de troca de cátions; C/N, relação C/N; CE, condutividade eletrolítica 
equipamento HP, modelo Agilent 1100, utilizando-se coluna cromatográfica Synergil Hydro-RP 80A $(250 \times 4,6 \mathrm{nmid} ; 4 \mu \mathrm{m})$. O tempo de corrida foi de $26 \mathrm{~min}$, ao fluxo de $0,7 \mathrm{~mL} / \mathrm{min}$, em temperatura de $24{ }^{\circ} \mathrm{C}$, sendo a identificação dos ácidos realizada em detector de arranjo diodo (DAD), em comprimento de onda de $220 \mathrm{~nm}$. Para as amostras de solo, foram injetados $100 \mu \mathrm{L}$ e para as de resíduos, o volume de injeção variou de 50 a $100 \mu \mathrm{L}$. No caso das amostras certificadas de ácidos orgânicos (padrões), o volume de injeção foi de $20 \mu \mathrm{L}$. Como solução eluente, foi utilizado $\mathrm{KH}_{2} \mathrm{PO}_{4} 20 \mathrm{mmol}$ $\mathrm{L}^{-1}, \mathrm{pH} 2,9$, conforme marcha analítica indicada pelo fabricante da coluna, com vistas à identificação de ácidos orgânicos presentes nas amostras sob investigação.

\section{Identificação e quantificação de ácidos orgânicos}

Como padrões analíticos, foram utilizados amostras certificadas da marca Supelco, sendo analisados os ácidos acético, fórmico, malônico, oxálico, quínico, chiquímico, tartárico, D-málico, maleico, succínico, cítrico e fumárico.

A curva analítica foi obtida relacionando-se a concentração do ácido com sua respectiva área de absorção. Os limites de detecção (LD) e quantificação (LQ) do método foram obtidos pela injeção de soluções analíticas de diferentes concentrações, preparadas por meio de diluições da solução padrão de trabalho. Assim, os LDe LQ para cada ácido orgânico foram estimados a partir da relação sinal/ ruído, calculada pelo software do equipamento, considerando-se, no mínimo, 3 e 10 vezes a razão do sinal pela linha de base (ruído), ${ }^{25}$ respectivamente (Tabela 3). A identificação dos ácidos orgânicos presentes nas amostras de solos e resíduos foi feita no cromatograma, com base no tempo de retenção de cada ácido e no perfil dos espectros de absorção no UV, sendo a quantificação feita por padronização externa. Ressalta-se que a as quantidades determinadas são as potencialmente extraíveis com a solução de $\mathrm{KH}_{2} \mathrm{PO}_{4}$.

\section{Análise estatística}

Por se tratar de um estudo de caracterização, as médias dos AOBMM determinadas nos materiais orgânicos foram apresentadas com seus respectivos desvios-padrão, sendo as análises realizadas em triplicata. As médias dos teores totais de AOBMM nos materiais foram submetidas à análise de variância e foi realizado o teste de Tukey, com nível de significância de 5\%, sendo empregado, nessa etapa, o programa estatístico SISVAR. ${ }^{26}$ Foram feitas análises de correlação de Pearson, bem como foi verificada a significância dos coeficientes de correlação, pela aplicação do teste t de Student.

\section{RESULTADOS E DISCUSSÃO}

Os teores e os tipos de ácidos orgânicos identificados nas amostras de solo e nos resíduos orgânicos são apresentados na Tabela 4. Dentre os solos avaliados, observou-se maior diversidade de AOBMM no LVdf e no NQ. Foram encontrados no LVdf os ácidos cítrico, fórmico, malônico e oxálico e, no NQ, os ácidos acético, malônico, oxálico, quínico e chiquímico. A presença do ácido fórmico apenas no LVdf pode estar relacionada à elevada concentração de ácido oxálico nesse solo. Quantidades estequiométricas de ácido fórmico e $\mathrm{CO}_{2}$ são produzidas durante a descarboxilação do ácido oxálico por bactérias que o utilizam como uma fonte de $\mathrm{C}$ e, por meio de uma série de reações que envolvem a coenzima $\mathrm{A}$, produzem o ácido fórmico. ${ }^{27,28}$

A concentração do ácido acético no LVAd e no NQ foi menor que o limite de quantificação desse ácido $\left(705 \mu \mathrm{mol} \mathrm{L}{ }^{-1}\right)$. Em solos bem aerados, como é o caso desses, são encontradas baixas concentrações de AOBMM, por período de tempo relativamente curto, pois são rapidamente degradados e utilizados por bactérias e fungos, ${ }^{29-31}$ no entanto, sob determinadas condições ambientais, como deficiência de oxigênio, estes ácidos podem ser acumulados até atingir concentrações tóxicas para o crescimento de plantas. ${ }^{10}$ Em arrozais inundados, por exemplo, as concentrações de ácido acético podem atingir $5000 \mu \mathrm{mol} \mathrm{L} \mathrm{L}^{-1} \mathrm{em} \mathrm{pH} \mathrm{6,5,} \mathrm{e} \mathrm{as} \mathrm{de} \mathrm{ácido} \mathrm{butírico,} \mathrm{entre} 100$ e $10000 \mu \mathrm{mol} \mathrm{L}{ }^{-1}, 32,33$ dependendo da quantidade e da qualidade do resíduo orgânico incorporado. ${ }^{34}$

Na maioria dos estudos realizados com vários tipos de solos e coberturas vegetais são relatadas concentrações de AOBMM na solução do solo menores que $50 \mu \mathrm{mol} \mathrm{L}^{-1},{ }^{6,35,36}$ podendo variar de 10 a $50 \mu \mathrm{mol}$ $\mathrm{L}^{-1}$ onde a disponibilidade de oxigênio é plena. ${ }^{37}$ Os ácidos monocarboxílicos (fórmico, acético, propiônico, láctico, butírico e valérico) são frequentemente encontrados em concentrações mais elevadas (até $1000 \mu \mathrm{mol} \mathrm{L}^{-1}$ ) na solução do solo do que di e tricarboxílicos, como malônico, oxálico, málico, succínico e cítrico. ${ }^{6,36}$ Isso se deve à maior capacidade das moléculas orgânicas com maior número de grupos funcionais, como $\mathrm{OH}$ e $\mathrm{COOH}$, serem mais efetivas na competição pelos sítios de adsorção que as de menor número. ${ }^{10} \mathrm{~A}$ utilização de $\mathrm{KH}_{2} \mathrm{PO}_{4}$ na extração dos ácidos orgânicos de amostras de solos, possivelmente, contribuiu para a falta dessa tendência, uma vez que

Tabela 3. Linearidade, limite de detecção (LD), limite de quantificação (LQ) e tempo de retenção $\left(t_{R}\right)$ dos ácidos orgânicos estudados

\begin{tabular}{|c|c|c|c|c|c|c|}
\hline Ácido orgânico & Linearidade $\left(\mu \mathrm{mol} \mathrm{L}{ }^{-1}\right)$ & Equação de regressão $^{(1)}$ & $\mathrm{r}$ & $\mathrm{LD}^{(2)}$ & $\mathrm{LQ}^{(3)}$ & $t_{R}(\min )$ \\
\hline Ácido oxálico & $10-2220$ & $y=0,098 x-0,373$ & 0,999 & 0,003 & 0,012 & 4,0 \\
\hline Ácido D-tartárico & $7-1330$ & $y=0,426 x+1,286$ & 0,999 & 0,015 & 0,049 & 4,7 \\
\hline Ácido quínico & $16-781$ & $y=1,335 x+0,939$ & 0,999 & 0,024 & 0,082 & 5,0 \\
\hline Ácido fórmico & $57-3259$ & $y=0,343 x+4,453$ & 0,998 & 0,037 & 0,125 & 5,3 \\
\hline Ácido D-málico & $37-1119$ & $y=0,919 x+2,922$ & 0,995 & 0,027 & 0,089 & 6,0 \\
\hline Ácido malônico & $480-2884$ & $y=0,696 x+34,39$ & 0,994 & 0,004 & 0,014 & 6,3 \\
\hline Ácido chiquímico & $6-862$ & $y=0,012 x+0,267$ & 0,999 & 0,0002 & 0,0008 & 7,3 \\
\hline Ácido acético & $693-4156$ & $y=1,848 x+4,209$ & 0,999 & 0,211 & 0,705 & 9,5 \\
\hline Ácido maleico & $9-1293$ & $y=0,006 x-0,285$ & 0,999 & 0,0003 & 0,001 & 10,6 \\
\hline Ácido fumárico & $9-1292$ & $y=0,007 x+4,021$ & 0,983 & 0,0001 & 0,0004 & 12,4 \\
\hline Ácido cítrico & $104-1302$ & $y=0,644 x-0,311$ & 0,999 & 0,037 & 0,119 & 12,7 \\
\hline Ácido succínico & $42-1271$ & $y=1,117 x-1,133$ & 0,999 & 0,122 & 0,406 & 15,2 \\
\hline
\end{tabular}

(1) y: concentração, $\mu \mathrm{mol} \mathrm{L}{ }^{-1}$; $\mathrm{x}$ : área do pico. ${ }^{(2)}$ Limite de detecção $\left(\mu \mathrm{mol} \mathrm{L} \mathrm{L}^{-1}\right)$, que é calculado como $\mathrm{S} / \mathrm{R}=3$. ${ }^{(3)}$ Limite de quantificação $\left(\mu \mathrm{mol} \mathrm{L}{ }^{-1}\right)$, que é calculado como $\mathrm{S} / \mathrm{R}=10$. 
Tabela 4. Teores $\left(\mu \mathrm{mol} \mathrm{kg}{ }^{-1}\right)$ de ácidos orgânicos em amostras de solo e de materiais orgânicos

\begin{tabular}{|c|c|c|c|c|c|c|c|c|c|c|c|c|}
\hline \multirow{2}{*}{ Amostra } & Acético & Cítrico & D-málico & Fórmico & Fumárico & Maleico & Malônico & Oxálico & Quínico & Chiquímico & Succínico & D-tartárico \\
\hline & \multicolumn{12}{|c|}{ - } \\
\hline LVdf & & $<\mathrm{LQ}$ & & $1275 \pm 171$ & & & $2028 \pm 37$ & $3504 \pm 123$ & & & & \\
\hline LVAd & $<\mathrm{LQ}$ & & & & & & & $1152 \pm 91$ & & & & \\
\hline NQ & $<\mathrm{LQ}$ & & & & & & $1770 \pm 19$ & $799 \pm 59$ & $<\mathrm{LQ}$ & $8,2 \pm 0,18$ & & \\
\hline E. galinha & $18582 \pm 1.046$ & $2221 \pm 739$ & $1633 \pm 372$ & & $276 \pm 81$ & & & $4860 \pm 99$ & & $42 \pm 5.6$ & & $23944 \pm 2.428$ \\
\hline E. suíno & $4217 \pm 204$ & & & $2289 \pm 102$ & & $9,3 \pm 0,3$ & & $568 \pm 25$ & $<\mathrm{LQ}$ & $19,3 \pm 2,5$ & & \\
\hline E. cavalo & & & & & & & & $906 \pm 87$ & & $46,0 \pm 0,7$ & & \\
\hline E. bovino & & & $650 \pm 56$ & & $206 \pm 1,3$ & & & $1846 \pm 103$ & & & & \\
\hline E. codorna & $37714 \pm 6.790$ & $2222 \pm 71$ & & & $195 \pm 4,4$ & & $2570 \pm 9,5$ & $1789 \pm 38$ & & $30,3 \pm 2,4$ & & $8125 \pm 888$ \\
\hline Serragem & & & & & & & & $310 \pm 1,0$ & & $58,5 \pm 2,45$ & & \\
\hline F. coco & & & $821 \pm 107$ & & & & & & & $46,0 \pm 3,11$ & & \\
\hline C. pinus & $<\mathrm{LQ}$ & & & & & $66,3 \pm 1,7$ & & $95 \pm 8,5$ & $926 \pm 3,5$ & $21,7 \pm 2,1$ & & \\
\hline C. café & & $551 \pm 89$ & $6244 \pm 48$ & & & $101 \pm 15$ & $4319 \pm 95$ & & & & & $1433 \pm 136$ \\
\hline Carvão & & & & & & & & & $1833 \pm 347$ & $9,7 \pm 0,06$ & & \\
\hline Lodo 1 & $14745 \pm 363$ & & $781 \pm 67$ & $12978 \pm 625$ & & & $5068 \pm 464$ & $1116 \pm 137$ & & $13,6 \pm 0,18$ & & \\
\hline Lodo 2 & $6382 \pm 435$ & & & $3618 \pm 74$ & & & & $1325 \pm 59$ & & & & $244 \pm 12$ \\
\hline Substrato & $4905 \pm 324$ & & & & & & $2537 \pm 33$ & $680 \pm 58$ & $<\mathrm{LQ}$ & & $2848 \pm 238$ & \\
\hline Turfa & & & & & & & & $2355 \pm 438$ & $<\mathrm{LQ}$ & & & \\
\hline C. lixo & & & & $10199 \pm 2.116$ & & $120 \pm 0,6$ & & $2961 \pm 143$ & & $17,4 \pm 0,1$ & & $454 \pm 52$ \\
\hline C. dejeto & $<\mathrm{LQ}$ & & & $1332 \pm 105$ & $193 \pm 2,6$ & & $2229 \pm 9,5$ & $1726 \pm 84$ & & $43,5 \pm 0,3$ & $<\mathrm{LQ}$ & $2370 \pm 48$ \\
\hline
\end{tabular}

$<\mathrm{LQ}=$ menor que o limite de quantificação

formas adsorvidas de AOBMM também são extraídas; considerando o LVdf, os ácidos orgânicos extraídos em maiores quantidades foram oxálico >malônico $>$ fórmico $>$ cítrico.

A presença do ácido chiquímico no NQ foi verificada em baixa concentração $\left(8,2 \mu \mathrm{mol} \mathrm{kg} \mathrm{kg}^{-1}\right)$. O ácido oxálico foi encontrado nas três amostras de solo, em concentrações que variaram de 799 a $3504 \mu \mathrm{mol} \mathrm{L}^{-1}$ (Tabela 4). Esses valores estão de acordo com os encontrados por Gonzalez et al., ${ }^{38}$ em que concentrações médias de ácido oxálico nos solos não rizosférico, rizosférico e ectomicorrízosférico foram de 600,1111 e $1730 \mu \mathrm{mol} \mathrm{kg}{ }^{-1}$, respectivamente. O ácido oxálico é produzido em sistemas naturais por um grande número de plantas e microrganismos, incluindo fungos e bactérias. ${ }^{27}$ Dentre os diversos ácidos orgânicos produzidos em quantidades significativas e encontrados na solução de solos florestais, os mais comumente identificados são o oxálico, cítrico e acético. ${ }^{1}$ Segundo Tani e Higashi, ${ }^{39}$ a presença dos ácidos cítrico e oxálico em solos é importante pelo fato de participarem da complexação de metais e da liberação de prótons, com efeito inclusive na formação e diferenciação de horizontes.

Os AOBMM fazem parte do ciclo do carbono e são fontes de energia para os microrganismos. ${ }^{40}$ Devido às propriedades ácida $\mathrm{e}$ quelante, esses ácidos são importantes no aumento da disponibilidade de formas insolúveis de nutrientes, como o fósforo, ${ }^{41} \mathrm{e}$, dessa forma, auxiliam na aquisição de nutrientes e no crescimento de plantas. Segundo Christ e David, ${ }^{42}$ condições de clima quente e úmido favorecem a síntese de ácidos orgânicos no solo e, portanto, exercem efeito direto sobre a atividade microbiana. Além disso, em solos ácidos e quimicamente pobres, a produção de exsudatos radiculares mais ricos em AOBMM de cadeia alifática pelas plantas é favorecida. ${ }^{43}$ Tani e Higashi ${ }^{39}$ identificaram, por meio da técnica HPLC, em perfis de solos no Japão, os ácidos fórmico, acético, propiônico, butírico, lático, oxálico, fumárico, succínico, málico e cítrico, o que, embora se tratem de solos em condições de clima temperado, está em acordo com os dados apresentados neste estudo em que os solos foram amostrados em área de mata nativa de clima tropical.

Os teores e tipos de ácidos orgânicos variaram entre os resíduos orgânicos, havendo resíduos, como a serragem, em que os teores e a diversidade de ácidos orgânicos foram reduzidos (Tabela 4). Por outro lado, os estercos de galinha e de codorna possuem elevados teores e grande diversidade de ácidos orgânicos. Os ácidos cítrico e oxálico, por exemplo, encontrados em ambos os resíduos, formam complexos mais estáveis com os metais do que outros AOBMM, tais como o fórmico e o lático. ${ }^{1}$ Dentre os resíduos avaliados, acredita-se que os estercos de galinha e de codorna, quando adicionados em solo, possam introduzir, inicialmente, maiores quantidades de AOBMM e afetar fortemente a mobilidade e a disponibilidade de nutrientes para as plantas.

Embora o procedimento de secagem das amostras de resíduos orgânicos seja idêntico ao realizado para as amostras de solo, verifica-se que as concentrações dos AOBMM de cadeia curta, com menores valores de temperatura de ebulição, como o acético e o fórmico, foram maiores nos materiais orgânicos do que em solos. $\mathrm{O}$ ácido acético foi encontrado na maioria desses materiais (estercos de galinha, suíno, codorna, composto de dejeto, lodo de esgoto 1 e 2, casca de pinus e substrato); o ácido fórmico foi encontrado no esterco de suíno, compostos de dejeto e de lixo e nos lodos 1 e 2. A atividade microbiana nesses materiais parece ser bastante elevada, de tal modo que, após a etapa de secagem, há síntese constante desses ácidos a partir da degradação de outros. Bolan et al. ${ }^{44}$ identificaram, por meio da técnica HPLC, uma pequena variedade e baixos teores de ácidos orgânicos em solo e em serrapilheira, enquanto que em composto de aviário foi observada a presença dos ácidos acético, cítrico, fumárico, lático, málico, oxálico, tartárico/fórmico, ressaltando a sobreposição de pico para os dois últimos ácidos. Os teores de ácidos orgânicos encontrados na amostra de composto de aviário variaram de 2980

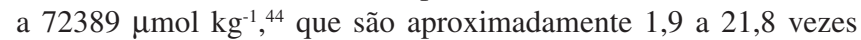


maiores que os obtidos em amostras de esterco de galinha e codorna no presente estudo. Vários fatores podem contribuir para as diferenças encontradas, como a espécie, idade e tipo de alimentação/ração que é fornecida às aves, grau de compostagem do material, bem como questões relacionadas ao preparo de amostras e o método analítico utilizado. Baziramakenga et al. ${ }^{45}$ verificaram maiores concentrações dos ácidos acético e fórmico em estercos frescos em relação aos estercos compostados e que maiores quantidades de AOBMM são extraídas quando se emprega uma solução saturada de $\mathrm{Ca}(\mathrm{OH})_{2} \mathrm{em}$ relação à água.

Além dos estercos de galinha e de codorna, outros resíduos orgânicos apresentaram grande diversidade de ácidos orgânicos, tais como o composto de dejetos de suínos, lodo de esgoto 1 e esterco de suíno. $\mathrm{O}$ ácido tartárico está presente em maiores quantidades no composto de dejeto de suínos. No lodo de esgoto e esterco de suínos, há predomínio do ácido acético. Em amostras de lodo de esgoto e estercos de galinha e codorna, Melo et al. ${ }^{46}$ identificaram uma grande diversidade de ácidos orgânicos, dos quais os ácidos oxálico, cítrico, málico e fórmico também foram encontrados neste estudo. $\mathrm{O}$ ácido oxálico foi identificado em todas as amostras avaliadas (exceto fibra de coco, casca de café e carvão), em concentrações variando de 95$4860 \mu \mathrm{mol} \mathrm{kg}{ }^{-1}$. Em estercos compostados, Baziramakenga et al. ${ }^{45}$ também verificaram predominância do ácido, em concentrações de 600 a $26600 \mu \mathrm{mol} \mathrm{kg}{ }^{-1}$.

As quantidades totais de AOBMM potencialmente extraíveis com o $\mathrm{KH}_{2} \mathrm{PO}_{4}$ são apresentadas na Figura 1. Dentre os solos avaliados, o LVdf apresentou maior quantidade de AOBMM (6955 $\mu \mathrm{mol}$ $\left.\mathrm{kg}^{-1}\right)$. Em ordem decrescente, os teores totais de AOBMM foram: $\mathrm{LVdf}>\mathrm{NQ} \geq \mathrm{LVAd}$, o que reflete a mesma ordem de teores totais de $\mathrm{C}$ presentes nesses solos (Tabela 1). No Japão, Tani e Higashi ${ }^{39}$ encontraram teores totais de AOBMM variando de 176 a $412 \mu \mathrm{mol} \mathrm{kg}{ }^{-1}$. No presente estudo, a faixa de concentração obtida foi de 2320 a 6955 $\mu \mathrm{mol} \mathrm{kg}{ }^{-1}$. Essas diferenças são atribuídas às características dos solos nos dois estudos, além de profundidade de amostragem, metodologia de extração dos ácidos orgânicos, clima e vegetação, que condicionam os teores de ácidos orgânicos em solos..$^{39}$ Os teores totais de AOBMM nas amostras de solos utilizadas neste estudo são mencionados com ressalva, uma vez que Jones et al. ${ }^{18}$ verificaram recuperação incompleta de AOBMM extraídos com solução de $\mathrm{KH}_{2} \mathrm{PO}_{4}\left(500 \mathrm{mmol} \mathrm{L}{ }^{-1}\right)$ a partir de horizontes subsuperficiais de solos minerais.

Somadas as quantidades de ácidos presentes nos resíduos, foi

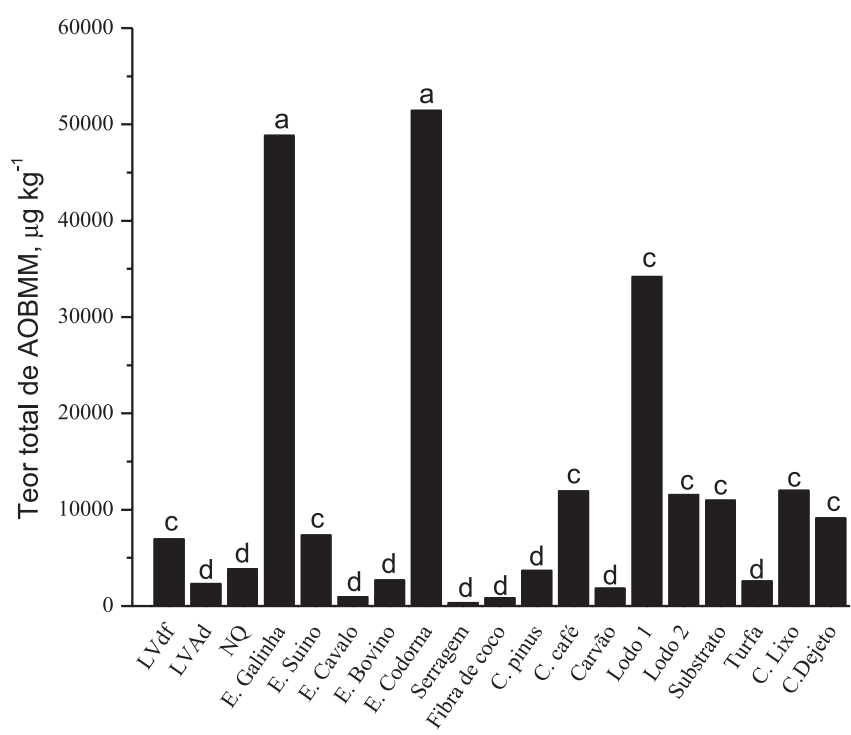

Figura 1. Teor total ( $\mu \mathrm{mol} \mathrm{kg}^{-1}$ ) de ácidos orgânicos de baixa massa molar (AOBMM) em amostras de solo e de resíduos orgânicos verificado maior teor de AOBMM nos estercos de codorna e galinha e no lodo 1; os estercos de cavalo e bovino, serragem, fibra de coco, casca de pinus, carvão e turfa foram os materiais com menores teores totais de ácidos orgânicos (Figura 1). A presença dos maiores teores de AOBMM nos estercos de galinha e de codorna se deve, entre outros fatores, ao fato de se tratarem de estercos frescos, não compostados e ricos em nutrientes, materiais lábeis e COEA (Tabela 2) e, portanto, de fácil decomposição pelos microrganismos. De modo geral, materiais orgânicos de fácil decomposição produzem maiores quantidades e diversidade de ácidos do que materiais mais resistentes. ${ }^{47}$

Os coeficientes de correlação de Pearson entre o teor total de AOBMM extraível com $\mathrm{KH}_{2} \mathrm{PO}_{4}$ e o teor de COEA e de nitrogênio das amostras (solos e resíduos) estudadas são, respectivamente, 0,69 e 0,73 . A análise estatística revelou que existe correlação forte e significativa $(\mathrm{P}<0,01)$ entre as variáveis estudadas. Valores positivos dos coeficientes de correlação mostraram que o teor total de AOBMM aumenta com o acréscimo dos teores de COEA e de N. Tais resultados estão de acordo com os dados obtidos por van Hees et al., ${ }^{5}$ que verificaram, para alguns perfis de solo, correlações positivas entre os teores totais de AOBMM com o COEA do solo. Xu et al. ${ }^{9}$ também verificaram que os teores totais de AOBMM se mostram dependentes do teor de $\mathrm{N}$ presente nos materiais vegetais incubados. Nesse mesmo estudo, a diversidade de AOBMM variou de um material vegetal para outro, sendo observados, em maiores concentrações, os ácidos oxálico, tartárico, acotínico, málico, cítrico, e, em concentrações muito baixas, os ácidos acético, lático, ascórbico e fórmico.

\section{CONCLUSÕES}

Em solos, foram encontrados os ácidos acético, cítrico, fórmico, malônico, oxálico, quínico e chiquímico e, em resíduos, além dos ácidos mencionados, foram identificados os ácidos D-málico, fumárico, maleico, succínico e tartárico.

O LVdf com textura argilosa e maior teor de COEA apresentou alta diversidade e maior quantidade de AOBMM que os demais solos.

As quantidades de AOBMM, potencialmente extraíveis, variam de 339 (serragem) a $51437 \mu \mathrm{mol} \mathrm{kg}^{-1}$ (esterco de codorna) e, nos solos, de 2320 (LVAd) a $6955 \mu \mathrm{mol} \mathrm{kg}{ }^{-1}$ (LVdf).

A concentração total de AOBMM é maior nos estercos que possuem elevado teor de COEA, como os de codorna e de galinha, do que nos solos e demais resíduos.

\section{MATERIAL SUPLEMENTAR}

Os cromatogramas de soluções padrões de ácidos orgânicos de baixa massa molar identificados neste estudo são apresentados na Figura 1S. Este material encontra-se disponível em http://quimicanova.sbq.org.br, na forma de arquivo PDF, com acesso livre.

\section{AGRADECIMENTOS}

À FAPEMIG (processo CAG - PPM-00424-09), pelo custeio das ações de pesquisa deste estudo. À CAPES, pelo fornecimento de bolsa PNPD à primeira autora e ao CNPq, pela concessão de bolsa de produtividade em pesquisa aos autores do estudo. Às alunas de iniciação científica, L. B. de Lima e A. de P. Naves, pela ajuda na condução do estudo.

\section{REFERÊNCIAS}

1. Fox, T. R.; Comerford, N. B.; Soil Sci. Soc. Am. J. 1990, 54, 1144

2. Bohnen, H.; Silva, L. S.; Macedo, V. R. M.; Marcolin, E.; Rev. Bras. Ciênc. Solo 2005, 29, 480. 
3. van Hees, P. A. W.; Jones, D. L.; Nyberg, L.; Holmstrom, S. J. M.; Godbold, D. L.; Lundstrom, U. S.; Soil Biol. Biochem. 2005, 37, 531.

4. van Hees, P. A. W.; Anderson, A. M.; Lundstrom, U. S.; Chemosphere 1996, 33, 1966.

5. van Hees, P. A. W.; Lundstrom, U. S.; Giesler, R.; Geoderma 2000, 94, 200.

6. Strobel, B.W.; Geoderma 2001, 99, 198.

7. EMBRAPA; Sistema brasileiro de classificação de solos, $2^{\text {a }}$ ed., EMBRAPA: Rio de Janeiro, 2006.

8. Singh, C. P.; Amberger, A.; Bioresour. Technol. 1998, 63, 16.

9. Xu, J. M.; Tang, C.; Chen, Z. L.; Soil Biol. Biochem. 2006, 38, 552.

10. Pavinato, P. S.; Rosolem, C. A.; Rev. Bras. Ciênc. Solo 2008, 32, 920.

11. Fu, M. H.; Ph.D. Dissertation, Iowa State University, United States, 1989.

12. McBride, R. G.; Mikkelsen, R. L.; Barker, K. R.; Appl. Soil Ecol. 2000, $15,151$.

13. Miyazawa, M.; Pavan, M. A.; Calegari, A.; Rev. Bras. Ciênc. Solo 1993, $17,416$.

14. Jones, D. L.; Darrah, P. R.; Plant Soil 1994, 166, 257.

15. Jones, D. L.; Prabowo, A. M.; Kochian, L.V.; Plant Soil 1996, 182, 247.

16. van Hees, P. A. W.; Jones, D. L.; Godbold, D. L.; Soil Biol. Biochem. 2002, 34, 1272.

17. Fox, T. R. Em Carbon Forms and Functions in Forest Soils; McFee, W. W.; Kelly, J. M., eds.; SSSA: Madison, 1995.

18. Jones, D. L.; Dennis, P. G.; Owen, A. G.; van Hees, P. A. W.; Plant Soil 2003, 248, 41

19. Boudot, J. P.; Geoderma 1992, 52, 39.

20. Jones, D. L.; Edwards, A. C.; Soil Biol. Biochem. 1998, 30, 1902.

21. Higashikawa, F. S.; Silva, C. A.; Bettiol, W.; Rev. Bras. Ciênc. Solo 2010, 34, 1752 .

22. Tedesco, M. J.; Gianello, C.; Bissani, C. A.; Bohnen, H.; Volkweis, S. J.; Análise de solo, plantas e outros materiais, $2^{\mathrm{a}}$ ed., UFRGS: Porto Alegre, 1995.

23. Scaglia, B.; Adani, F.; J. Environ. Sci. 2009, 21, 646.

24. Silva da, F. C.; Abreu, M. F.; Pérez, D. V.; Eira, P. A.; Abreu, C. A.; van Raij, B.; Gianello, C.; Coelho, A. M.; Quaggio, J. A.; Tedesco, M. J.; Silva, C. A.; Cantarella, H.; Barreto, W. O. Em Manual de análises químicas de solos, plantas e fertilizantes; Silva da, F. C., ed.; EMBRAPA: Brasília, 1999, cap. 3.
25. Snyder, L. R.; Kirkland, J. J.; Glajch, J. L.; Practical HPLC method development, $2^{\text {nd }}$ ed., Wiley: New York, 1997.

26. Ferreira, D. F.; SISVAR-Versão 4.6; Universidade Federal de Lavras, Brasil, 2003.

27. Hodgkinson, A. Em Oxalic acid metabolism in higher plants; Hodgkinson, A., ed.; Academic Press: London, 1977.

28. Allison, M. J.; Cook, H. M.; Science 1981, 212, 676.

29. Schwartz, S. M.; Varner, J. E.; Martin, W. P.; Soil Sci. Soc. Am. Proc. 1954, 18, 177.

30. Hollis, J. P.; Rodriguez-Kabana, R.; Phytopathology 1966, 56, 1019.

31. Lynch, J. M. Em Advances in Soil Organic Matter Research: The Impact on Agriculture and the Environment; Wilson, W. S., ed.; Royal Society of Chemistry: Cambridge, 1991.

32. Stevenson, F. I. Em Organic Acids in Soil;, McLaren, A. D.; Peterson, G. H., eds.; Soil Biochemistry: New York, 1967.

33. Lynch, J. M.; Soil Biol. Biochem. 1978, 10, 135.

34. Camargo, F. A. de O.; Santos, G. de A.; Rossielo, R. O. P.; Pesq. Agropec. Bras. 1993, 28, 1018

35. Baziramakenga, R.; Simard, R. R.; Leroux, G. D.; Soil Biol. Biochem. 1995, 27, 356.

36. Strobel, B. W.; Bernhoft, I.; Borggaard, O. K.; Plant Soil 1999, 212, 121.

37. Jones, D. L.; Plant Soil 1998, 205, 44.

38. Gonzalez, J. A. Z.; Costa, M. D.; Silva, I. R.; Neves, J. C. L.; Barros, N. F.; Borges, A. C.; Rev. Bras. Ciênc. Solo 2009, 33, 554.

39. Tani, M.; Higashi, T.; Eur. J. Soil Sci. 1999, 50, 226.

40. Martinez, C. E.; Kleinschmidt, A. W.; Tabatabai, M. A.; Biol. Fertil. Soils 1998, 26, 163.

41. Kpomblekou-A, K.; Tabatabai, M. A.; Soil Sci. 1994, 158, 453.

42. Christ, M. J.; David, M. B.; Soil Biol. Biochem. 1996, 28, 1199.

43. Marschner, H.; Mineral Nutrition of Higher Plants. $2^{\text {nd }}$ ed., Academic Press: London, 1995.

44. Bolan, N. S.; Naidu, R.; Mahimairaja, S.; Baskaran, S.; Biol. Fertil. Soils 1994, 18, 319.

45. Baziramakenga, R.; Simard, R. R.; Leroux, G. D.; J. Environ. Qual. 1998, 27, 561 .

46. Melo, L. C. A.; Silva, C. A.; Dias, B. O.; Rev. Bras. Ciênc. Solo 2008 , 32,110 .

47. Harper, S. H. T., Lynch, J. M.; J. Sci. Food Agric. 1981, 32, 1062. 